\section{International Journal of Research in Social Science and Humanities (IJRSS)}

DOI: http://doi.org/10.47505/IJRSS.2020.9138
E-ISSN : 2582-6220

Volume 1, Issue 4

Sep-Oct - 2020

\title{
Spiritual Fitness and Community Welfare
}

\author{
Latifa Belfakir \\ Professor, Sidi Mohammed Ben Abdallah University, \\ Department of English Studies, \\ Fes, Morocco
}

\begin{abstract}
Spiritual fitness has become a hot subject since the outbreak of COVID- 19. The World Health Organization, in 1948, defined health as " not merely the absence of disease or infirmity. ... it is a complete state of physical, mental and social well being." Later on the spiritual dimension was added ensuring that health stems from an amalgam of bodily, mental, social wellbeing in addition to spiritual fitness. The belief that spirituality may help people attain meaning through experiencing humanity in all aspects of life has in the last decade moved to academia and excited many researchers. Thus, in social sciences, like leadership studies, researchers have recognized the importance of individual spirituality (spiritual fitness) and how it could be achieved through a comprehensive and balanced life individually and in communities. In this sense, contemporary research has in a thought-provoking way suggested that the spiritual domain should be seen as an integral element of societal development.
\end{abstract}

Keywords: Resilience, Spirituality, Spiritual Fitness, COVID-19 pandemic, Spiritual coping.

\section{INTRODUCTION}

It is spontaneously assumed that certain types of fitness,- physical, psychological and mental- are prerequisites to a healthful lifestyle since they provide the means to lead a fully meaningful and purposeful life. They are obviously important to the healthy co/existence of individuals and communities, alike. Yet, it is not immediately obvious (a) how spiritual fitness is likely to enhance the body and help it to adapt to inner threats and infirmities; (b) how it boosts individuals' resilience and readiness to adapt to change and crises and (c) how it can make groups and organizations strive in times of trouble.

Besides, for many people, spiritual beliefs influence their perspective on the world tremendously, offer comfort and peace of mind in tumultuous times, and provide support from considerate and neighborly community members. Such beliefs may thus chip in building people's resilience and lead to improved efficiency and ultimately to their prosperity both as individuals and as communities. This paper embraces the concept of spiritual fitness as a long-forgotten route to the attainment of personal positive malleability and wellbeing especially in the chaotic context of disasters. The definition of resilience adopted for this article is, indeed, a broad definition proposed by Almedom and Tumwine (2008):

... resilience is defined as the capacity of individuals, families, communities, systems, and institutions to anticipate, withstand and/or judiciously engage with catastrophic events and/or experiences; actively making meaning with the goal of maintaining normal function without fundamental loss of identity.

The article starts with an overview of the key constructs of spirituality and spiritual fitness, as presented in the literature and their relationship to physical wellbeing, psychological pliancy in addition to individual and group welfare are identified. Besides, it should be mentioned that the choice of this topic has exceptionally been energized by a personal cognizance of a general decline of the human values, roles, and relationships, in general and in the COVID-19 times, more specifically. Thus the article also aims at explaining how lack of spiritual fitness can account for the diverse individual differences in emotional, cognitive and behavioral responses to one of life's most stressful events which is the unprecedented and globally destructive pandemic caused by the Coronavirus. Thirdly, the article ends up by reiterating the efficacy of spiritual interventions and targeting the components or indicators of spiritual fitness. Thus, my main objective in this paper, as a fervent advocate of spiritual fitness, is to preach for the virtues of a return to spirituality for those who aim to regain a balanced life both as individuals and as members of their respective groups and communities. 


\section{ON DEFINING SPIRITUALITY}

Spirit comes for the Latin word spiritus, meaning breath, as in the breath of life. "Spirit, the unseen force that infuses and energizes, that gives us energy and life, gets covered up in individuals and organizations in which the executive-as-leader casts a large shadow," as Moxley stated (2000, p. 9). Hence, spirituality is defined as the human belief in, movement toward, and relationship with a higher purpose or power, self, and others from which a sense of purpose, consciousness, interconnectedness, and destiny may be derived (Swift, 2003). The spiritual journey is a dynamic process where individuals seek to discover their potential, purpose, and a personal relationship with a higher power that may or may not be called God (Wulff, 1996).

The literature on spirituality is disconcerting since it is not only limited in its content, but there is hardly any consensus among authors on the definition of the term 'spirituality', itself. Rayburn and Rayburn (1996) stated, for instance, that spirituality is the vital force of one's being. It is the inner self where values and morality are located (Fairholm, 1997). Mitroff and Denton (1999) more admirably defined spirituality as "the basic feeling of being connected with one's complete self, others, and the entire universe." (p. 83). Conger and Kanungo (1994) suggested that it is often related to a particular feeling of sacredness or transcendence often associated with a source of selfless love. Unlike the previous conceptions of spirituality, Vaill (1998) presented it as a continuous and transient state where one decides to open one's self to a transcendent source of meaning where learning becomes a way of being. In addition, Turner (1999) added that spirituality pertains to our hopes and dreams, our patterns of thought, our emotions, feelings and behaviors. It is true, thus, that spirituality as a conception is ubiquitous and multifaceted; yet, its meaning, as Turner puts it, is inevitably lost when attempts are made to capture it in a few words. In sum, spirituality goes through a movement away from competitive status seeking towards self-sufficiency, self-probe, personal development, where a non-materialistic form of gratification is manifest.

Perhaps one of the most complete definitions of spirituality was formulated by Puchalski, Ferrel, Virani, Otis-Green \& Bull, as "the aspect of humanity that refers to the way individuals seek and express meaning and purpose, and the way they experience their connectedness to the moment, to self, to others, to nature, and to the significant or sacred" (Puchalski et al., 2009). Spirituality is a complex and multidimensional part of the human experience, as an inner belief system. It helps individuals to search for the meaning and purpose of life, and it helps them to experience hope, love, inner peace, comfort, and support (Saad \& Medeiros, 2012).

Besides, according to 3000-year-old traditional Chinese Medicine \& pharmacy, which are profoundly influenced by traditional Chinese philosophy and religion, spirituality is an innate human aptitude where the mind, body, and spirit of a person are inseparable. Spiritual nourishment is key old method of treatment in China. Thus, in order to have good health one must have good spirit and pay attention to cultivating one's spirit (Shi, Zhang, 2012). Present-day Western medical specialists have increasingly insisted that the links between the spiritual and health facets of the human being are not trivial. Indeed, there is some evidence of links between spirituality and improvements in people's mental health, evidenced by the integration of the spiritual dimension into psychotherapy in the first half of the $20^{\text {th }}$ century (Laszlo, 1954). Thus, the relationship between our physical wellbeing and our spiritual fitness has been recognized by the East and today, even in the West it is being acknowledged.

Thanks to revealed efforts of governments, global and local health agencies in addition to individual experts' attempts, the four segments of human existence have been forcefully acknowledged, namely (a) the body (physical), (b) mind (logical/rational thought), (c) heart (emotions/feelings), and (d) spirit (Moxley, 2000). Yet, despite all the endeavors to praise the benefits of spiritual well-being in counter-attacking life-threatening diseases and disasters, only a few individuals decided to embark on a spiritual quest while many laypeople's interest in developing their spiritual stance is still lagging behind.

\section{SPIRITUALITY AND RELIGION}

Besides, researchers (Koenig, 1997) have tried to investigate the relationship between spirituality and another similar construct, namely religion. For many, spirituality may be used interchangeably with religion (Korac-Kakabadse et al., 2002), as spirituality, like religion, is often associated with a closeness to God and feelings of interconnectedness with the world. For some others, like James (1902), religion is a deep individual experience from which the outcome is the "loss of all work, the sense that all is well with one, the peace, harmony, the willingness to be" (p. 248). Miller (1999), in the same line of thought, stated that spirituality “includes one's capacity for creativity, growth, and the development of a values system" (p. 30). In this sense, spirituality is like a moral compass which leads an individual to having a sense of peace and purpose. Spirituality also stems from the meaning we build of life in connection with others.

The Dalai Lama XIV (1999) provided an interesting distinction between spirituality and religion by assuming that the latter is akin to faith, traditions, and a system of beliefs or formalized practices and ideas. Spirituality is, however, related to qualities of the 
human spirit, such as compassion, patience, love, tolerance, forgiveness, contentment, personal reasonability, including a sense of environmental harmony. Hence, the Dalai Lama XIV claimed that spirituality is a necessity for religion, but religion is not a prerequisite to spirituality.

In contrast, others have viewed spirituality and religion as independent terms (Zinnbauer, Pargament, Cole, et al., 1997; Zinnbauer, Pargament, \& Scott, 1999). Spirituality is often representative of the broader concept and represents beliefs and values, while religion is narrower and refers to practices (Chandler, Holden, \& Kolander, 1992). Thus, while spirituality is, in this viewpoint, larger in scope and more abstract, religion is more practical, being endorsed via behaviours, acts and verbal practices as well. This makes religion, as a consequence, just one of the many reflections of spirituality. For Shafranske and Malony (1985), religion is not even the primary source of spirituality. Therefore, spiritual fitness per se may not require any degree of religiosity or belief in the supernatural. In this view, even atheists, though they hold a secular philosophy of meaning and purpose, can be spiritually fit while the most religious may lack spirituality as he/she practices his/her religion like an automaton and without seeing any spiritual meaning in that.

For others, religion and spirituality are tightly linked, yet, they exert different influences on one's health. They claim that spiritual fitness, being abstract in nature, is "fitness of the spirit or soul, especially from a religious aspect" (Hufford, Fritts, and Rhodes, 2010). Religiosity, in this sense, may serve as a route to better health habits, such as lower smoking rates and reduced alcohol consumption and spirituality helps regulate emotions, which aids physiological effects such as blood pressure (Aldwin, Park, Jeong, Nath, 2014). Indeed, when a religion is embraced, the dictates conveyed in this faith act like a code of conduct to believers. The latter are, thus supposed to observe the prescriptions imposed by the religion and abstain from what is forbidden. Besides, the spiritually fit is likely to reach high degrees of inner peace, and bodily fitness, as a consequence.

\section{SPIRITUAL FITNESS}

In 1985, the World Health Organization decided to acknowledge spiritual fitness as an important dimension in the wellbeing of human beings. And since then, spiritual fitness has become a decisive component in the quality of every individual's life. In other words, how someone fares spiritually affects that person's physical, psychological, and interpersonal states, and vice versa. Besides, spiritual fitness can come in many forms and may include any of the following rudiments: engagement with a community with similar values, altruism, a sense of morality, belief in transcendent meaning and purpose, self-transcendence, religiosity, religious and/or spiritual practices, in addition to exceptional experiences, such as visions or perceived communications with the deceased (Hood, 1975).

Thus, pursuing spiritual fitness involves both the tangible and intangible dimensions of individuals' lives. However, the latter dimension (values, emotions, social skills, relationships) is more likely to impact greatly the quality of physical aspects of individuals. Spiritual fitness is assigned many definitions in the literature. In the Spiritual Fitness Leaders Guide Notebook of the United States Marine Corps, it is identified as "the ability to adhere to beliefs, principles, and values needed to persevere and prevail” ( cited in Yeung \& Martin, 2013:5). Thus, one's level of persistence to attain a goal and degree of success may depend very much on how spiritually fit one is. In addition, it is also believed that spiritual fitness is simultaneously affected by 'self' (factors related to the individual) and 'greater than self' (factors external to the individual). Examples of the first category would be abilities, personality, experience and goals while the 'greater than self' elements could be religion, philosophy of life, family and friends (Spiritual Fitness Leaders Guide Notebook, p.9). In this sense, for a full-fledged spiritual fitness to be attained, the individual should also rely on the communities -religious or non-religious- he/she belongs to for mutual support, assistance and recognition.

Aside from that, it is believed that spiritual fitness leads and is related to well-being in multiple ways. For instance, it is enormously related to,- but not the direct equivalent of,- psychological well being. Although these two dimensions are interrelated, psychological wellbeing focuses on the study of the psyche, while spiritual wellbeing goes to the core of a person (Fisher, 2011). Besides, when spiritual fitness intersects with the psychological wellbeing, it gives birth to 'psycho-spiritual fitness' (Yeung \& Martin, 2013:6). Thus, any kind of psycho-spiritual fracas, like stress may be the result of a crisis of values, meaning, and purpose; a disturbance of the psycho-spiritual equilibrium due, maybe, to a misalignment within one's core spiritual beliefs. Psychological imbalances can, in effect, lead to both spiritual and health disruptions; and as Larry Trivieri Jr., a recognized authority on alternative medicine puts it, "prolonged stress can result in suppressed immune function, increased susceptibility to infectious and immune-related diseases and cancer" (www.healthworld.com). Thus, a spiritual faux pas can be conducive to a psychological hitch which may in turn be the cause of bodily problem.

In effect, having a sense of meaning and purpose in life is tightly linked to psychological well-being and better perceived quality of life. It can enhance one's mental health too helping one manage stressful situations and all types of angst. That's why, people 
are advised to practice spiritual exercises, like mediation, and yoga, or use of spiritual beliefs to enhance their spiritual fitness and, bumper physiological stressors and pains.

Another pillar of spiritual fitness is called perceived self-efficacy, and it is, as Bandura puts it, "concerned with judgments of how well one can execute courses of action required to deal with prospective situations" (1982, p. 122). Put simply, self-efficacy emanates from the conviction that individuals have about their capacities-general and specific- to perform tasks. Seen in this line of reasoning, spiritual fitness is likely to be uplifted behaviorally. In other words, the behaviorally-fit individuals tend to adopt healthy lifestyles and habits. Indeed, behavior fitness, which is defined by Shih et al. (2015), as the knowledge, skills, and behaviors necessary to successfully protect oneself from stress associated with one's environment, gives one a strong impetus to develop one's resilience in order to effectively resist stressors of all kinds.

In effect, judgments like the ones we have about our efficiency are likely to influence our choices in life in general, and determine the amount and quality of effort we make on tasks and chores. And they are also decisive factors that adjust our responses to traumatic experiences. Thus, the lower someone's self- efficacy, the lower his/her self- esteem and the higher his/her assertion of his/her own weaknesses. And this is ultimately likely to lead him/her to have no resilience in front of adversity, reacting negatively when pressured by nerve-racking problems.

In addition, mindfulness is another mainstay of psychological fitness (Hufford, Fritts, \& Rhodes, 2010). Mindfulness is most commonly defined as "the state of being attentive to and aware of what is taking place in the present" (Brown and Ryan, 2003, p. 822). It has a positive impact on improving mental wellbeing and decreasing stress (Zollars, Poirier \& Pailden, 2019). It is also believed that thanks to mindfulness, self-regulation can be endorsed. It helps individuals avoid engaging in maladaptive automatic behaviors and thoughts which may lead to chaotic behaviors and feelings. In addition, studies have proved that practicing mindfulness can lead to long-term benefits. A study (Solhang, et, al., 2019) checked a group of participants four years after their mindfulness training and found that the group scored much better on mindfulness and coping than those who haven't attended that course.

It seems that social fitness is also firmly connected to spiritual fitness. The former refers to "the aspects of social relationships that strengthen a person's ability to withstand and rebound from challenges (e.g., stress, threat, or disaster) or even grow from them" (McGene, 2013, p. vii). The core spiritual factor associated with social fitness is social belonging and support that is acquired from and through any of the social groups with which one identifies, starting from the nucleic family, through friends, neighbors, colleagues, cyber-community members to the larger fellow citizens. Social support can be realized in one of three forms, according to McGene (2013). It can be emotional, such as informal psychological counseling from a friend; instrumental, such as getting a home repair or a loan. Social support can also be informational. For example, shared knowledge in frequent and constructive social interactions and social media has proven very effective in increasing social connectedness and social support among like-minded people everywhere. All in all, given, its versatility and complexity, spiritual fitness is evidently a blend of many components that link the individual to the outside world, including the human, the material and non material.

\section{DIMENSIONS OF SPIRITUAL FITNESS}

Yeung and Martin (2013) identified four major components of spiritual fitness, namely, spiritual worldview, personal religious and spiritual practices, support from a spiritual/religious community, and spiritual coping. The first construct, which is spiritual worldview, includes beliefs in transcendent meaning and purpose (Yeung \& Martin, 2013, p.17). It encompasses commonsensical values as well as above the average ones. Some typical values of the former class could be, according to Litz and associates (2009), hope, peace, optimism, morality and altruism. Besides, self-transcendence is a remarkable representative of the more prestigious category of values that give spiritual fitness its exceptional feel. Self-transcendence aims to regain the original "interconnectedness of humanity, the natural world, or a higher being" (Elkins et al., 1998). It fastens the link between the human and a superior being or power.

The second component refers to personal religious or spiritual practices and rituals, such as mindfulness, and adherence to any spiritually uplifting conduct, like meditation, or taking part in religious activities and worshipping a deity. The efficacy of prayers and other spiritual practices on human morale and body has been researched by many scientists (Byrd, 1988). In this sense, Moberg (2005) showed how prayers had preventive and healing capacities. These prayers generate peace, power, and health that protect individuals from both psychological disorders like anxiety, and physical ill-being or health disease. In addition, prayers were seen to help restore patients after disasters and surgery. Similarly, Baldwin and associates (2008) argued that veterans reached high levels of spiritual well being thanks to their participation in religious or spiritual rituals with their comrades. 
Besides, one should not exclude the other expressions and practices of faith apart from religion, and admit, therefore, that spiritual fitness can be promoted in a variety of ways. Spiritual rituals can be expressed implicitly or explicitly as an individual or as a group. They can be outwardly performed as well as in silence, inside or outside a place of worship. They may take the form of solemn attendance to seminars and service in the church or performance of the Friday prayer in the mosque. Spiritual rituals may also be promoted more smoothly given that the connection to the element of faith is artlessly or candidly built in the person. Thus, religious practice turns out to be obsolete.

The third component is directly related to a quality that all human beings share. It seems that our bodies respond positively when we are in close contact with our nearest and dearest ones or when we bond socially with our community members. Research (Uvnas-Meberg \& Petersson, 2005) proved that when we are in close contact with 'our' people, our bodies release the 'love hormone' Oxytocin, whose stress-reducing effects have been proved. This construct refers to support from a spiritual community, be it religious or non religious. It depends, for example, on the extent and type of participation of individuals in their respective spiritual communities and the type and extent of support which the latter put at their disposal, as a consequence (LaRocca-Pitts, 2009).

Besides, spiritual fitness seekers can take a multitude of paths and support. Support from a spiritual or religious community adds up to the social facet of spiritual fitness. Members of a religious community meet, share and collaborate on different levels during and/or after religious rites and ceremonies. It is, however, noted that the more powerful the religious affiliations are the stronger the nodes built among members of the same religious network tend to be. Thus, individuals who share similar religious convictions, belong to the same cult or fit in the same congregation have the same religious affinities and tend to be more understanding of and supportive towards one another than with outcasts or those who hold different religious beliefs (Pargament et al., 1998).

Moreover, Mitroff and Denton (1999), after years of study and practice, stated that at the managerial level, many of the problems today's organizations have are due to their "impoverished spiritually" (p. xiii). That's why it would be foolish to go on being blind to appraising and "treating organizations as spiritual entities" (ibid, p. xiv). By the same token, leaders can obviously guarantee followers' confidence, nurture their intrinsic motivation, and boost a long-lasting commitment to the organization and shared goal by being in tune with the basic human needs of people (Fry, 2005).

It is, unfortunately, true that both religion and spiritual differences have been used over time to discriminate against people because of their beliefs. However, as social distancing has become the new norm due to the threats of COVID-19, the pressures of keeping wise contact with like-minded others have been at stake. Besides, even if social media are bridging the physical gap, nobody knows where the limit of our tolerance of physical isolation is.

Fourthly, it is tacitly believed by researchers, like Pargament and associates that spiritual beliefs and practices can affect the way people understand health and determine the strategies they use to cope with illness, including resilience resources ... (Hilbers, Haynes, Kivikko, Ratnavyuha, 2012). In other words, spiritual coping can happen when beliefs (religious and/or spiritual) are used so as to soothe individuals' psychological injuries caused by pressures and stress (Pargament et al., 1998). It seems that the complacency caused by these beliefs is also likely to lead to better worldview.

In fact, research indicates that stress not only lowers our immune responses, but it also increases the risk of getting diseases and may lengthen the duration of our illness. That's why, specialists have insisted on maintaining our inner serenity especially in emergency times. Therefore, spirituality might be particularly helpful in times of chaos, struggle, and distress; it helps alleviate nerve-racking feelings, and endorse positive ones. It is also firmly believed that spirituality can eventually positively influence immune, cardiovascular (heart and blood vessels), hormonal, and nervous systems.

Scholars have conducted many studies on the relationship between religion/spirituality and a wide range of physical and mental health conditions. They showed how high blood pressure, cerebro-vascular disease, heart disease, immune system dysfunction, improved subjects' ability to cope with cancer, chronic illness, longevity (Koenig, McCullough \& Larson, 2007). Likewise, spirituality has received interest in health-care services (Swinton \& Pattison, 2020) where spiritual support has been considered indissoluble from physical, social and psychological care because together they form one whole. If one facet is undermined, one or all the others are likely to suffer too. That's why, all preventive medicine has begun to reckon with health in a comprehensive view, in terms of bodily, psychological, and spiritual wellbeing.

As a matter of fact, spiritually-fit people are expected to be well-equipped to fit in the uncertain, messy world of global quarantine and social distancing. Thus, connecting through social media platforms with a like-minded, a community member, or reaching out for a more abstract type of connection with a spiritual power will not just combat our loneliness, especially in the times where 
self-isolation is imposed, but it will also reduce the higher cortisol levels associated with stress and boost our immunity, as a result ((Pendry, Vandagriff, 2019).

\section{CONCLUSION}

All in all, the focus of this paper was not to explore any particular religion in depth; instead, it explores how religious beliefs and other day-to-day practices may influence individual coping capacities and enhance their wellbeing, in general. The paper, thus, boasts about the perquisites of spirituality, in general, and insists that building spiritual fitness is a long journey that involves the development of four main components, namely spiritual worldview, belonging to a spiritual community, spiritual support, and spiritual coping.

\section{REFERENCES}

Aldwin C.M., Park C.L., Jeong Y.J., Nath R. (2014). Differing pathways between religiousness, spirituality, and health: a selfregulation perspective. Psychology Religion Spiritual;6(1):9-21. DOI:10.1037/a0034416.

Almedon, A. M. \& Tumwine, J. K. (2008). Resilience to Disasters: A Paradigm Shift from Vulnerability to Strength. Afr Health Sci. 2008 Dec; 8(Suppl 1): S1-S4.

Baldwin, C. P., Grant, R.N., Wendel, M.S., Rawl, S. Schmidt, C. M., Richard L., Krouse, R. S.(2008). Influence of Intestinal Stoma on Spiritual Quality of Life of U.S. Veterans Journal of Holistic Nursing 10.1177/0898010108315185 http://jhn.sagepub.com hosted at http://online.sagepub.com

Bandura, A. (1982). Self-Efficacy Mechanism in Human Agency the American Psychological Association, Inc. Vol. 37, No. 2, 122-147 0003-066X/82/3702-0122\$00.75

Brown, W., M. \& Ryan, R., M. (2003). The Benefits of Being Present: Mindfulness and Its Role in Psychological Well-Being. Journal of Personality and Social Psychology. The American Psychological Association, Inc., Vol. 84, No. 4, 822-848 00223514/03/\$12.00 DOI: 10.1037/0022-3514.84.4.822

Byrd RC.(1988). Positive therapeutic effects of intercessory prayer in a coronary care unit population;81(7):826-9.

Chandler C.K, Holden J.M., Kolander C.A. (1992). Counselling for Spiritual Wellness: Theory and Practice. Journal of Counseling Development.;71:169-75.

Chandrashekar, P. (2018). Do Mental Health Mobile Apps Work: Evidence and Recommendations For Designing High-Efficacy Mental Health Mobile Apps. Health, 4 (3).

Conger, J. A., \& Kanungo, R. N. (1987). The empowerment process: Integrating theory and practice. Academy of Management Review, 13, 471-482. Conger, J. A., \& Kanungo, R. N. (1994). Charismatic leadership in organizations: Perceived behavioral attributes and their measurement. Journal of Organizational Behavior, 15(5), 439-453.

Elkins, D.N., Hedstrom, L. J., Hughes, L.L., Leaf, J.A. and Saunders, C. (1988). 'Toward a humanistic-phenomenological spirituality: definition, description, and measurement'. Journal of Humanistic Psychology, 28: 5-18.

Fairholm, G. W. (1997). Capturing the heart of leadership: Spirituality and community in the new American workplace. Westport, CT: Praeger.

Fisher J. (2011). The Four Domains Model: Connecting Spirituality, Health and Well-being. Religions ;2:17-28.

Fry, L. W. (2005). Introduction to The Leadership Quarterly special issue: Toward a paradigm of spiritual leadership. The Leadership Quarterly, 16(5), 619-622.

Hilbers J, Haynes A, Kivikko J, Ratnavyuha D. (2012). Spirituality/Religion and Health Research report (phase two). Sydney: Koenig HG. Religion, spirituality, and health: the research and clinical implications. ISRN Psychiatry.

DOI:10.5402/2012/278730. Print 2012. 27. 
Hood, Ralph W., Jr., “The Construction and Preliminary Validation of a Measure of Reported Mystical Experience,” Journal for the Scientific Study of Religion, Vol. 14, No. 1, March 1975, pp. 29-41.

Hufford, David J., Matthew J. Fritts, and Jeffrey E. Rhodes. (2012). “Spiritual Fitness,” in Wayne B. Jonas, Francis G. O'Connor, Patricia Deuster, and Christian Macedonia, eds., Total Force Fitness for the 21st Century: A New Paradigm, Supplement to Military Medicine, Vol. 175, No. 8, http://www.siib.org/news/1099-

SIIB/version/default/part/AttachmentData/data/ Total\%20Force\%20Fitness\%20for\%20the\%2021st\%20CenturyA\%20New\%20Paradigm.pdf

James, W. (1902). The variety of religious experience. Cambridge, MA: Harvard University Press. Jones-Johnson, N. F. (2001). The relationship between spirituality and leadership practices of female administrators in higher education. Unpublished doctoral dissertation, Baylor University, Waco, TX.

Koenig HG, McCullough ME, Larson DB. Handbook of religion and health. New York: Oxford University Press; 2001.SESIAHS; 2007

Korac-Kakabadse, N., Kouzmin, A., \& Kakabadse, A. (2002). Spirituality and leadership praxis. Journal of Managerial Psychology, 17(3), 165-182.

LaRocca-Pitts, M. (2009). In FACT, chaplains have a spiritual assessment tool.Australian Journal of Pastoral Care and Health,3(2),8-15

Laszlo,V.S (Ed). (1954).The basic writings of CG Jung. New York: Random House.

Litz, B. T., Stein, N., Delaney, E., Lebowitz, L. NW. P. Nash, Silva, C. Maguen, S. (2009) Moral injury and moral repair in war veterans: A preliminary model and intervention strategy Clinical Psychology Review 29 695-706

McGene, J. (2013). Social Fitness and Resilience: A review of Relevant Constructs, Measures and Links to Well-being. RAND Project AIR FORCE series on Resilency.

Miller, G. (1999). The development of the spiritual force in counseling and counselor education. Journal of Counseling \& Development, 77, 498-501.

Mitroff, I. I., \& Denton, E. A. (1999). A spiritual audit of corporate America: A hard look a spirituality, religion, and values in the workplace. San Francisco: Jossey-Bass.

Mober, D. O. 42005). Research in Spirituality, Religion and Aging. Journal of Gerontological Social Work, 45 (1/2), $11-40$.

Moxley, R. S. (2000). Leadership and spirit. San Francisco, CA: Jossey-Bass. Neal, J. A. (2001). Leadership and spirituality in the workplace. In R. N. Lussier \& C. F. Achua (Eds.), Leadership theory, application, skill development (pp. 464-473). New York: South Western.

Pargament, K. I., Smith, B. S. Koenig, H. G. \& Perez, L. (1998). Patterns of Positive and Negative Religious Coping with Major Life Stressors. Journal for the Scientific Study of Religion. Vol. 37, No. 4, pp. 710-724

Puchalski, C.M., Ferrell, B., Virani, R., Otis-Green, S., Baird, P., Bull, J. (2009). Improving the quality of spiritual care as a dimension of palliative care: The Report of the Consensus Conference. 12(10), 885-904.

Rayburn, J. M., \& Rayburn, L. G. (1996). Relationship between Machiavellianism and type A personality and ethical-orientation. Journal of Business Ethics, 15(11), 1209-1220.

Saad, M. \& De Medeiros R. (2012). Spiritual-Religious Coping - Health Services Empowering Patients' Resources DOI: http://dx.doi.org/10.5772/50445

Shafranske, E. P., \& Malony, N. H. (1985). Religion, spiritual, and psychotherapy: A study of a California psychologist. Paper presented at the meeting of the California State Psychological Association, San Francisco.

Shih, Regina A., Sarah O. Meadows, and Margret T. Martin, Medical Fitness and Resilience: A Review of Relevant Constructs, Measures, and Links to Well-Being, 54 Santa Monica, Calif.: RAND Corporation, RR-107-AF, 2013. As of October 2013: http://www.rand.org/pubs/research_reports/RR107.html Spiritual Fitness Leaders Guide Notebook (2009). 
Shi, L., Zhang, C. (2020). Spirituality in Traditional Chinese Medicine. Pastoral Psychol 61, 959-974 (2012). https://doi.org/10.1007/s11089-012-0480-x

Solhang, I. deVibe, M., [...] \& Rosenvinge, J.H.; (2019). Long-term Mental Health Effects of Mindfulness Training: a 4-year Follow-up Study. Mindfulness 10, 61661- 1672.

Swift, J. (2003). Spiritual prescriptions for organizations: New strategies for change. Unpublished doctoral dissertation, The Fielding Institute, Santa Barbara, CA.

Swinton J, Pattison S. (2010). Moving beyond clarity: towards a thin, vague, and useful understanding of spirituality in nursing care. 11(4):226-237. DOI: 10.1111/j.1466-769X.2010.00450.x.

Turner, J. (1999). Spirituality in the workplace. CA Magazine, 132(10), 41-42. Vaill, P. (1989). Managing as a performing art. San Francisco: Jossey-Bass.

Trivieri, L. Jr, The Health plus Letter, Vol. 2, No. 2, www.1healthyworld.com.

Uvnas-Moberg \& Petersson, M. (2005). Oxytocin, a Hormone mediator of anti-stress, well-being, social interaction, growth and healing. Zeitschrift fur Psychosomatische Medizin und Psychtherapie, 51 (1), 57- 80. http://doi.org/10.13109/zpm.2005.51.1.57

Vaill, P. (1998). Spirited leading and learning. San Francisco: Jossey-Bass. Vaill, P. (2000). Introduction to spirituality for business leadership. Journal of Management Inquiry, 9, 115-116.

Vally, Z. \& D’Souza, C.G. (2019). Abstinence from S Muse Subjective well-being, Stress and Loneliness. Perspectives in Psychotic Care, 55(44). 752-759.

World Health Organization.org. (1985). Handbook of Resolutions and Decisions, Vol. II, p.5-6 2. The determinants of health. Geneva: World Health Organization. Available from: http://www.who.int/ hia/evidence/doh/en

Wulff, D. M. (1996). Psychology of religion: Classic and contemporary. New York: Wiley

Yeung, Douglas, and Margret T. Martin, Spiritual Fitness and Resilience: A Review of Relevant Constructs, Measures, and Links to Well-Being, Santa Monica, Calif.: RAND Corporation, RR-100-AF, 2013. As of October 2013: http://www.rand.org/pubs/research_reports/RR100.html

Zinnbauer, B., Pargament, K. I., Cole, B., Rye, M. S., Bufter, E. M., \& Belavich, T. G. (1997). Religion and spirituality: Unfuzzing the fuzzy. Journal of the Scientific Study of Religion, 36(4), 549-564.

Zinnbauer, B. J., Pargament, K. I., \& Scott, A. B. (1999). The emerging meanings of religiousness and spirituality: Problems and prospects. Journal of Personality, 67(6), 889-919.

Zollars, I., Poirier, T. I. \& Pailden, J. (2019). Effects of mindfulness meditation on mindfulness, mental well-being, and perceived stresss. Currents in Pharmacy Teaching and Learning, 11 (10). 1022-1028; 